\title{
PRÁCTICAS LETRADAS EN LÍNEA: LA APLICACIÓN DE QUIP EN LA REDACCIÓN DE ESTUDIANTES UNIVERSITARIOS
}

\author{
Miguel Ángel Malpartida* \\ Universidad Peruana de Ciencias Aplicadas \\ arsnriz@hotmail.com
}

Fecha de recepción: agosto de 2016 Fecha de aceptación: diciembre de 2016

RESUMEN: El presente artículo expondrá el proceso y los resultados de una investigación, realizada en una universidad privada de Lima, acerca de la aplicación de la plataforma de escritura colaborativa Quip en la redacción grupal e individual de los alumnos. La metodología utilizada recurrió a la observación y la elaboración de instrumentos. Más exactamente, se trató del uso de cuestionarios y entrevistas para la recopilación de datos. Seguidamente, por un lado, los cuestionarios ayudarán a revisar los vínculos y posibilidades a partir del diagnóstico de los hábitos letrados en línea. Por otro lado, permitirán ver los vínculos y posibilidades a partir del diagnóstico

Miguel Ángel Malpartida estudió Literatura en la UNMSM y Educación para el Desarrollo en la Pontificia Universidad Católica del Perú. Ha publicado los poemarios Galería (Lima: Dedo Crítico, 2002) y Arte de nariz (Lima: Mesa Redonda, 2007), así como artículos de crítica literaria en revistas especializadas, nacionales e internacionales. Ha laborado como docente del curso Seminario de Literatura en la Universidad Católica Sedes Sapientiae. Actualmente, se desempeña como profesor del Área de Humanidades en la Universidad Peruana de Ciencias Aplicadas. 
del uso de Quip. Después, las entrevistas brindarán más opiniones de docentes y alumnado acerca de la aplicación de dicha plataforma. Por último, se exhibirán las conclusiones obtenidas a partir del análisis de todos los datos obtenidos.

Palabras Clave: Quip, redacción universitaria, estrategias didácticas, análisis cualitativo.

\section{ONLINE LETTER PRACTICES: THE APPLICATION OF QUIP IN THE DRAFTING OF UNIVERSITY STUDENTS}

AвSTRACT: This article will present the process and the results of a research carried out in a private university in Lima about the application of the collaborative writing platform Quip in the group and individual writing of the students. The methodology used resorted to observation and the development of instruments. More precisely, it involved the use of questionnaires and interviews for data collection. Then, on the one hand, the questionnaires will help to review the links and possibilities from the diagnosis of online literate habits. On the other hand, will allow to see the links and possibilities from the diagnosis of the use of Quip. Then, the interviews will provide more opinions of teachers and students about the application of this platform. Finally, the conclusions obtained from the analysis of all the data obtained will be displayed.

KeYwords: Quip, university writing, didactic strategies, qualitative analysis. 
PRÁCTICAS LETRADAS EN LÍNEA: LA APLICACIÓN DE QUIP EN LA REDACCIÓN DE ESTUDIANTES UNIVERSITARIOS

\section{Introducción}

$\mathrm{E}$

1 artículo expondrá el proceso y los resultados de una investigación, realizada en una universidad privada de Lima, acerca de la aplicación de la plataforma de escritura colaborativa Quip en la redacción grupal e individual de los alumnos. En esta investigación, se realiza e interpreta diagnósticos sobre las prácticas letradas en línea, en general, y sobre el uso de Quip, en particular, enfocados tanto en los alumnos como en los docentes del curso. De igual manera

El objetivo general de la investigación consiste en analizar el modo en que la utilización de Quip, una plataforma de escritura colaborativa, integra las prácticas letradas en línea de los alumnos en el proceso de redacción de textos académicos. Los objetivos específicos de la investigación son los siguientes: (a) identificar las prácticas letradas en línea que pueden ser empleadas en el proceso de enseñanza y aprendizaje de la redacción, y (b) valorar la funcionalidad de Quip, una plataforma de práctica letrada en línea, en el desarrollo de las etapas de la redacción y su didáctica.

\section{Marco Teórico}

\subsection{Las prácticas letradas en línea y el aprendizaje}

Desde una perspectiva sociocultural de la didáctica de la redacción, Cassany (2012) afirma que las prácticas letradas, es decir, "cada forma cultural de una comunidad humana concreta que utiliza un escrito para hacer algo", han devenido en entornos cada vez más tecnológicos. Para el autor, esto se debe al empleo permanente de la escritura, con todos los procesos cognitivos que este saber y práctica supone (Cassany, 1999), en las comunicaciones que 
las personas entablan vía Internet, a través de soportes físicos digitales, lo cual denomina literacidad digital (Cassany, 2008). De forma específica, las ha llamado también prácticas letradas en línea (Cassany, 2012).

Estas actividades escritas han delimitado, gradualmente, nuevas prácticas y géneros textuales situados sociohistóricamente en una comunidad, organizados en torno a las instituciones, y que resultan cada vez más indispensables para el desarrollo de la vida cotidiana, para la formación de la ciudadanía, y, en concordancia con ello, para el aprendizaje y la educación (Cassany, 2008). Asimismo, se considera que la inserción de los hablantes en estas nuevas comunidades supone también el desarrollo de nuevas habilidades. Preferentemente, tales habilidades son contextualizadas al margen de las instituciones educativas formales (Cobo y Moravec, 2011) o ubicadas en puntos intermedios de inserción (Cassany, 2012).

Particularmente, con respecto a estos espacios liminares, Cassany (2012) señala que el aprovechamiento de la lectura y la escritura en las redes puede presentarse como un hecho que favorece y complementa el aprendizaje de los contenidos curriculares mediante la propuesta de una serie de artefactos sofisticados y específicos para cada área o materia. Entre las varias propuestas didácticas, destaca el empleo de las plataformas de aprendizaje. Estas, asumidas desde la enseńanza institucionalizada, configuran los entornos virtuales de aprendizaje (EVA), cuya modalidad de enseñanza debe ser colaborativa para ser exitosa, o, por el contrario, se ponen en práctica desde una modalidad más libre y cotidiana, denominada entornos personales de aprendizaje (EPA), caracterizados por la autonomía del aprendiz que busca el conocimiento de modo independiente e intuitivo.

Asimismo, Cassany (2012) señala que los objetivos que debe perseguir el empleo de las prácticas letradas en la red en función del trabajo en el aula son los siguientes: (a) identificar y valorar los aprendizajes que 
realizan los alumnos en la red; (b) establecer lazos entre las prácticas vernáculas y las académicas; y (c) adaptar y flexibilizar los programas y las prácticas a los entornos digitales de los alumnos, o colaborar en la mejora del desempeño de los aprendices en la red, ya sea fuera o dentro del currículo oficial.

\subsection{Géneros discursivos aplicados a la didáctica de la escritura}

Cassany (2012) realiza una clasificación de los géneros discursivos surgidos a partir de las prácticas letradas en la red. Entre los plenamente digitales, y específicamente entre los asincrónicos, ubica a varias de las herramientas que han potenciado la educación en los últimos años: los foros, los blogs, las wikis, los chats y las redes sociales, y los más genéricos (el correo y la web). Cada uno de estos géneros, según el autor, presenta ventajas y dificultades específicas. Sin embargo, es conveniente señalar las posibilidades didácticas más importantes en función del aporte que pueden brindar a la enseñanza de la redacción como podrá apreciarse en la Tabla 1. 


\section{MIGUEL ÁNGEL MALPARTIDA}

\section{Tabla 1}

\section{Posibilidades Didácticas de los Géneros Discursivos en Linea, según Daniel Cassany}

\begin{tabular}{lll}
\hline Géneros & \\
\hline Foros & $\bullet$ & Proponer preguntas y respuestas de comentario de texto. \\
& $\bullet$ & Realizar lluvia de ideas o puesta en común, así como debates organizados y revisión \\
& cooperativa de escritos en forma de taller de escritura.
\end{tabular}

Blogs - Elaborar una bitácora o portafolio en el que puede registrar datos y pruebas de su aprendizaje y reflexionar sobre estos

- Narrar experiencias personales o de sus gustos

- Anotar datos sobre tareas escolares fuera del aula.

- Desarrollar un tema curricular con vínculos a recursos de la red.

- Trabajar individualmente o grupalmente, y observar el trabajo de sus compañeros.

Wikis - Gestionar actividades, es decir, administrar las labores de clase.

- Almacenar contenidos, o sea, repositorio o también sitios para sistematizar un tema.

- Trabajar en equipo, es decir, tarea de redacción colaborativa.

- Redactar una narración a varias manos, o sea, recurso para elaborar narraciones en grupo o practicar los procesos de composición de textos (generación de ideas, redacción y revisión).

Chat - Promover el diálogo entre profesores y alumnos fuera del aula en tareas formales, espacios de apoyo, trabajo en parejas de revisión y elaboración de escritos, comentarios de lecturas, aclaración de dudas, formulación de entrevistas, preparación de exámenes, gestión y actualización de wikis con los coautores.

- Para el uso pedagógico de este medio en una tarea planificada y organizada, fuera de la intención de las redes sociales, se requiere establecer las siguientes pautas: (a) número limitado de participantes, (b) moderación del docente, (c) turnos preestablecidos, (d) intervención previa de todos los estudiantes y valoración posterior del docente, (e) implicación obligatoria de los alumnos y (f) uso obligatorio de un registro especializado y correcto.

Redes - Aprovechable para configurar entornos de aprendizaje aunque con ciertas limitaciones, sociales debido a que simplifican y uniformizan las prácticas letradas. Para aprender, se requiere de habilidades como "el manejo de discursos técnicos, monologados y específicos, con argumentación rigurosa y minuciosa, muy alejados de la cháchara espontánea” (p. 236), las cuales pueden desarrollarse a partir de prácticas verbalmente más sofisticadas e interactivas como las webs, los libros, las conversaciones o los blogs.

Nota. Adaptado de "En_línea. Leer y escribir en la red," por D. Cassany, 2012. Barcelona, Espańa: Anagrama. 


\section{PRÁCTICAS LETRADAS EN LÍNEA: LA APLICACIÓN DE QUIP EN LA REDACCIÓN DE ESTUDIANTES UNIVERSITARIOS}

La visión desesperanzada de Cassany (2012) con respecto a las redes sociales como fuente de aprendizaje tiene su contraparte en una serie de estudios enfocados en los hábitos de los estudiantes universitarios en la red. Estos sustentan las posibilidades de usar estas nuevas prácticas como herramientas o entornos de aprendizaje formal y no formal. En este sentido, UNL Virtual (2011) ha concluido, a partir de encuestas, que la frecuencia de uso de las TIC para desarrollar actividades académicas aumenta con el rango de edad y el grado académico alcanzado.

Asimismo, Artero (2011), citado en Islas y Carranza (2011), ha precisado que las redes sociales constituyen herramientas que no pueden ser obviadas, ya que "el eje de todas ellas se adscribe a la interacción y capacidad de responder y comunicar con rapidez y elocuencia" (p. 15). De acuerdo con ello, Gómez, Roses y Farías (2012) citado en Valenzuela (2013), ha indicado que el uso de las redes favorece la publicación de información, el aprendizaje autónomo, el trabajo en equipo, la comunicación, la realimentación, el acceso a otras redes afines y el contacto con otros expertos. Esta interacción se da entre estudiantes en general, así como entre estudiantes y profesores, lo que facilita el aprendizaje constructivista y el aprendizaje colaborativo.

En este contexto, además, se ha realizado estudios acerca del desempeño lingüístico de los estudiantes en la red. Sobre este aspecto, Martínez (2013) afirmó que, si bien los estudiantes presentan una aparente deficiencia en cuanto al ritmo de lectura de los textos que "deberían leer", ello no significa que no participen de una cultura escrita que excede, frecuentemente, el soporte del libro físico. Incluso, dicha cultura puede ser más o menos sofisticada en cuanto a lo analítico.

Estos nuevos ámbitos de lectura y escritura se focalizan actualmente en dos tipos de plataformas de uso generalizado. Por un lado, las redes sociales son estructuras virtuales que se basan en el contacto de las personas por 
medio de una plataforma o sitio web. Son ejemplo de estas Facebook, Twitter, Instagram, LinkedIn, etc. Por otro lado, la mensajería instantánea es una forma de comunicación en tiempo real entre dos o más personas a través de un texto escrito y recursos visuales predeterminados, que se realiza por medio de dispositivos conectados a la red. Algunos ejemplos son WhatsApp y Messenger de Facebook. A continuación, en la Tabla 2, se resume las posibilidades didácticas atribuidas a dos aplicaciones de uso generalizado en el denominado Mobile Learning o aprendizaje a través de los dispositivos móviles.

\section{Tabla 2}

\section{Posibilidades Didácticas de Facebook y WhatsApp}

\begin{tabular}{|c|c|}
\hline Plataformas & Posibilidades didácticas \\
\hline $\begin{array}{l}\text { Facebook } \\
\text { (red social) }\end{array}$ & $\begin{array}{l}\text { - Utilización como una comunidad de interpretación, es decir, un medio para } \\
\text { compartir, analizar y opinar sobre textos de interés común, que ha generado una } \\
\text { tensión en cuanto al uso de los soportes papel y electrónico (Martínez, 2013). } \\
\text { - Función integradora (fuera de su rol socializador) de las prácticas de comunicación } \\
\text { letrada en la red: ha incorporado la sociabilidad de otros medios electrónicos a } \\
\text { través de la inclusión de funciones como el chat, mensajería instantánea y blogs } \\
\text { (Martínez, 2013). } \\
\text { - Inclusión en el diseño instruccional de los cursos formales bajo las condiciones de } \\
\text { la "e-moderación" del profesor coaching y las "e-actividades", fundamentadas en el } \\
\text { diálogo constante e interactivo en forma de comunidad (Rocha, s.f.). } \\
\text { - Resultados positivos a partir de la vinculación entre los hábitos de los estudiantes } \\
\text { en Facebook y la potencialidad educativa de su aplicación en las actividades } \\
\text { grupales académicas (Chiecher \& Donolo, 2013). }\end{array}$ \\
\hline $\begin{array}{l}\text { Whats App } \\
\text { (mensajería } \\
\text { instantánea) }\end{array}$ & $\begin{array}{l}\text { - Debido al ahorro en mensajería celular, su uso es sumamente frecuente en la } \\
\text { población estudiada para socializar, pero también es aplicable a la coordinación de } \\
\text { actividades académicas entre alumnos. } \\
\text { - Posibilidad de compartir imágenes de organizadores gráficos y esquemas, de modo } \\
\text { grupal o individual, con el docente como paso previo a la textualización. } \\
\text { - Elaboración de foros para responder preguntas que aporten a la comprensión de } \\
\text { las fuentes, así como para proponer y discutir consignas de redacción. } \\
\text { - Grabación y envío de archivos de voz para revisar la planificación textual o } \\
\text { fragmentos breves de la reescritura, tanto entre alumnos o en la retroalimentación } \\
\text { docente-alumno. } \\
\text { - Resultados positivos como complemento de la enseñanza-aprendizaje fuera del } \\
\text { aula (Morató, 2014). }\end{array}$ \\
\hline
\end{tabular}




\section{PRÁCTICAS LETRADAS EN LÍNEA: LA APLICACIÓN DE QUIP EN LA REDACCIÓN DE ESTUDIANTES UNIVERSITARIOS}

\subsection{Escritura colaborativa en línea}

La escritura colaborativa se define como una estrategia de escritura grupal que, aplicada con fines didácticos, supone la regulación socialmente compartida, entendida como "procesos de co-construcción de un mutuo entendimiento de la tarea, el establecimiento compartido de objetivos y las actividades de planeación, ejecución y evaluación que los estudiantes realizan como grupo para resolver conjuntamente una tarea de escritura colaborativa” (Castelló, Bañales \& Vega, 2010, p.1275, citados en Arenas Hernández, 2014). Al trasladar el concepto de escritura colaborativa al uso que se les puede dar en la red, Sanz y Sangara (2012) establecieron que aquella se puede clasificar como una e-actividad, es decir, una actividad de aprendizaje gestionada a partir de las herramientas propias de un entorno de mediación vía medios digitales en conectividad. Entre ellas pueden figurar, por ejemplo, los foros, los espacios colaborativos, un entorno de videoconferencia, etc.

El aporte más interesante de estas autoras estriba en la necesidad de integrar, en la escritura colaborativa en línea, los EVA, por ejemplo, las aulas virtuales institucionales, con los EPA que los alumnos y sus docentes tienen a disposición para su aprendizaje autónomo, verbigracia, las redes, los foros, las wikis y las plataformas de escritura colaborativa. De acuerdo con ello, las actividades que se planifiquen deben modularse según una serie de fases, las cuales, tal como se apreciará en la Tabla 3, siguen las etapas del diseño didáctico de la redacción. 
MIGUEL ÁNGEL MALPARTIDA

\section{Tabla 3}

Secuencia Didáctica de una Actividad de Escritura Colaborativa en Linea

\begin{tabular}{|c|c|}
\hline Fases & Características \\
\hline 1. Diseńo de la consigna & $\begin{array}{l}\text { Incluye la generación de un documento individual a partir de } \\
\text { fuentes de investigación y la producción de un documento grupal } \\
\text { que vincule el aporte de todos. }\end{array}$ \\
\hline 2. Armado de grupos & $\begin{array}{l}\text { Se prefiere que los integrantes sean multidisciplinarios para asumir } \\
\text { varias perspectivas. }\end{array}$ \\
\hline $\begin{array}{l}\text { 3. Definición de las her- } \\
\text { ramientas y posibilidades } \\
\text { de seguimiento por parte } \\
\text { de los docentes }\end{array}$ & $\begin{array}{l}\text { Establecimiento de una herramienta "natural" y eficiente para la } \\
\text { práctica de escritura colaborativa, tanto en los EVA como en los } \\
\text { EPA. }\end{array}$ \\
\hline $\begin{array}{l}\text { 4. Tareas de acompañamiento } \\
\text { del tutor }\end{array}$ & $\begin{array}{l}\text { Estas son fuentes de consulta, monitoreo de la participación de los } \\
\text { alumnos y seguimiento de las entregas. }\end{array}$ \\
\hline $\begin{array}{l}\text { 5. Autoevaluación del tra- } \\
\text { bajo individual y grupal }\end{array}$ & Estructura de "macrogrupos" e instrumentos. \\
\hline 6. Cierre & $\begin{array}{l}\text { Síntesis o trabajo final de cada grupo, análisis, devolución a los } \\
\text { alumnos (análisis del proceso y del producto), y comunicación de } \\
\text { los resultados. }\end{array}$ \\
\hline
\end{tabular}

Nota. Adaptado de "La escritura colaborativa como una e-actividad," por C.

Sanz y A. Zangara, 2012. Recuperado de http://sedici.unlp.edu.ar/bitstream/ handle/10915/23661/4810-La_escritura_colaborativa_como_una_e_final.pdf;jses sionid=C60DDC4AF71CEB843F395214F33B8157? sequence $=1$

Finalmente, (a) los aportes sobre los géneros discursivos surgidos a partir de las prácticas letradas en línea (Cassany, 2012), (b) las experiencias didácticas con dichos géneros en las redes y la mensajería instantánea (Carrera, Sapién \& Piñón (s.f.); Martínez, 2013; Rocha, s. f.; Chiecher \& Donolo, 2013; Morató, 2014); (c) la determinación de los roles en la redacción colaborativa de los alumnos (Arenas, 2014); y (d) la propuesta de un diseño didáctico de la redacción colaborativa en línea por medio de fases que integran los entornos EVA y EPA (Sanz \& Sangara, 2012) serán muy importantes para la presente investigación. 
Lo anterior se debe a que dichos aportes sostienen la indagación de las tres variables que estructuran los instrumentos que se aplicarán. Estas son las que siguen: (a) identificación de las prácticas letradas en líneas aplicadas a la didáctica de la redacción; (b) valoración de la plataforma Quip en el desarrollo de las etapas de la redacción y (c) descripción de la inclusión de Quip en el desarrollo de estrategias didácticas de un curso de redacción.

\subsection{Quip: generalidades, funciones, ventajas, desventajas $y$ posibilidades}

Quip es un procesador de textos creado en el 2013 que se encuentra disponible para plataformas móviles y de escritorio con un fuerte énfasis en la colaboración y creación de contenidos para la red. Fue creado por el exdirector técnico de Facebook, Bret Taylor, y por Kevin Gibbs, creador, en Google, del sistema que sugiere las búsquedas mientras se escribe en el buscador. Estos han resaltado que Quip es una respuesta al anquilosamiento de los procesadores de textos usados desde la década de 1980, cuyo diseño no se ha adaptado al avance de los nuevos dispositivos, por ejemplo, las tablets y los smartphones (Díaz, 2013).

Asimismo, según el testimonio de sus diseñadores, apoyado en su diseño minimalista, Quip pretende recrear y recuperar la experiencia de la escritura colaborativa en papel, que debiera ser sencilla, fácil, inmediata y agradable, y eliminar el continuo compartir de versiones de un mismo documento y la proliferación de correos electrónicos de coordinación (Díaz, 2013). Al respecto, en el blog de página web de Quip (https:/quip. $\mathrm{com} / \mathrm{blog}$ /introducing-quip), los diseñadores subrayan cuatro ventajas que trascienden la utilización de los procesadores de texto existentes. Estos son los que siguen: colaboración, movilidad, interactividad y simplicidad. 
Como muchos de los aplicativos de escritura, Quip tiene una versión descargable gratuita (la cual se emplea en esta investigación) y una versión de paga. Asimismo, está disponible para los sistemas móviles IOS y Android, y su versión para PC puede ser empleada desde todos los navegadores asociada a una cuenta Google. A continuación, en la Tabla 4, se identifica las funciones de Quip.

\section{Tabla 4}

\section{Quip: Funciones}

Funciones de Quip

1. Chat con los usuarios del documento o carpeta

2. Sala de chat también fuera del documento

3. Administración de documentos y carpetas (crear nuevo, adicionar, compartir, copiar, mover, ordenar, asignar colores)

4. Opción de compartir el documento con usuarios y no usuarios de Quip

5. Visualización de los documentos en lista y en cuadrícula con marcas de editores y actualizaciones

6. Notificaciones al dispositivo cuando hay cambios en el documento

7. Procesador de texto (letra, tamaño, viñetas, inserción de imágenes y tablas, etc.)

8. Edición offline (sin conexión a la red) que se actualiza al iniciar sesión.

9. Exportar el documento a formatos de procesador de texto (PDF, Word, Excel, etc.)

10. Añadir integración (exportar el documento a Twitter, Dropbox, Gmail, Email, etc.)

11. Bandeja de entrada (solicitudes, recibidos, destacados, sin leer, leídos, mensajes directos, privados, creados por mí)

Observado de modo objetivo, Quip sintetiza numerosas posibilidades de uso acordes con las atribuidas en el marco teórico a las prácticas letradas en línea, los géneros discursivos, la escritura colaborativa en línea y el diseño didáctico de esta. A continuación, se sintetizarán otras potencialidades del mencionado procesador de textos: 
- Quip puede considerarse una herramienta integradora de las prácticas letradas en línea, ya que (a) unifica el empleo de los siguientes géneros discursivos: chat, blog, foro, wiki, chat; (b) hace posible la exportación a los procesadores de texto tradicionales y (c) permite la integración a redes sociales y a la mensajería instantánea.

- Quip puede emplearse como una herramienta de redacción colaborativa, lo cual supone las siguientes posibilidades: (a) la producción simultánea de un documento en tiempo real por dos o más redactores que se asumen conscientemente como coautores, y (b) el proceso de negociación, organización, determinación e intercambio de roles propios de la escritura colaborativa.

- Quip puede emplearse como una plataforma que complemente la enseñanza de la redacción, puesto que abre la posibilidad de diseñar estrategias didácticas de redacción colaborativa que consideran las fases de la redacción académica y la integración, en estas, de los EVA y los EPA de alumnos y docentes.

Es a partir de estas hipótesis que se elaboró los instrumentos de análisis que se explican en el siguiente apartado.

\subsection{Quip y el diseño didáctico de Comunicación en la Unidad 1}

La universidad incluida en la investigación se encuentra en un proceso de innovación tecnológica institucional que extiende su primera fase desde el 2014 hasta el 2018. Este incluye (a) la adopción de un soporte institucional (iPad), (b) la incidencia en la capacitación de los docentes en el uso de las aplicaciones EVA y EPA vinculadas con tal dispositivo y (c) el 
traslado cada vez más frecuente de los cursos presenciales a la modalidad blended o semipresencial. Frente a este panorama, en el semestre 2016-I se realizó el diseño del curso de Comunicación, el cual desarrolla la competencia de comunicación escrita de los alumnos de los primeros ciclos de la Facultad de Ciencias de la Salud, y es el único curso específico del Área de Lenguaje dedicado a dicha facultad, en todas las mallas de las carreras que la integran.

Desde sus inicios, sin participar directamente de la ipadización o de la blenderización, se imprimió al curso un diseño amigable con el uso de plataformas virtuales educativas para apoyar el proceso de redacción colaborativa. Más aún, en el semestre 2016-II, este interés se acentuó en un intento de acompañar al proceso de innovación tecnológica institucional y de aprovechar todos los beneficios que esta provee (préstamo de dispositivos, capacitaciones en aplicaciones con fines educativos además del aula virtual). De acuerdo con ello, se propuso consolidar este aporte a través de la adopción de estrategias complementarias de redacción colaborativa en línea diseñadas en torno a plataformas de acceso libre. Ello supuso el apoyo de la Coordinación General de Lenguaje y la propuesta, por parte de la Coordinación de Comunicación, de actividades que incluyeron plataformas de escritura colaborativa en la red como Quip o Google Docs en el diseño de las evaluaciones grupales del curso. En la Tabla 5, se apreciará la inclusión de Quip como estrategia didáctica de la Unidad 1 de una de las secciones donde se lleva el curso de Comunicación. 


\section{PRÁCTICAS LETRADAS EN LÍNEA: LA APLICACIÓN DE QUIP EN LA REDACCIÓN DE ESTUDIANTES UNIVERSITARIOS}

\section{Tabla 5}

\section{Diseño de Actividades Quip en una Sección de Comunicación}

\begin{tabular}{|c|c|c|}
\hline $\begin{array}{l}\text { Evaluaciones } \\
\text { Unidad } 1\end{array}$ & Actividades Quip & Productos \\
\hline TA & $\begin{array}{l}\text { Revisión de fuentes: chat, edición de documento } \\
\text { Planificación: imagen insertada } \\
\text { Redacción preliminar: edición de documento } \\
\text { Retroalimentación 1: chat, edición de documento } \\
\text { Reescritura: chat, edición de documento } \\
\text { Retroalimentación 2: chat, edición de documento } \\
\text { Calificación: chat, edición de documento }\end{array}$ & $\begin{array}{l}\text { Participación en foro } \\
\text { Organizador/esquema }\end{array}$ \\
\hline PrePC & $\begin{array}{l}\text { Revisión de fuentes: chat } \\
\text { Planificación: }\end{array}$ & $\begin{array}{l}\text { Participación en foro } \\
\text { Organizador/esquema }\end{array}$ \\
\hline $\mathrm{DD}$ & $\begin{array}{l}\text { Revisión de fuentes: chat, edición de documento } \\
\text { Planificación: imagen insertada } \\
\text { Redacción preliminar: edición de documento } \\
\text { Retroalimentación 1: chat, edición de documento } \\
\text { Reescritura: chat, edición de documento } \\
\text { Retroalimentación 2: chat, edición de documento } \\
\text { Calificación: chat, edición de documento }\end{array}$ & $\begin{array}{l}\text { Participación en foro } \\
\text { Organizador/esquema }\end{array}$ \\
\hline TP & $\begin{array}{l}\text { Revisión de fuentes: chat, edición de documento } \\
\text { Planificación: chat, edición de documento } \\
\text { Redacción preliminar: chat } \\
\text { Retroalimentación 1: chat } \\
\text { Reescritura: chat }\end{array}$ & $\begin{array}{l}\text { Participación en foro } \\
\text { Organizador/esquema }\end{array}$ \\
\hline
\end{tabular}

La estructura de las actividades mostrada es afín a la propuesta de Sanz y Sangara (2012) para el diseño de actividades de redacción colaborativa en la red.

\section{Metodología}

La presente investigación empleó un diseño cualitativo. Para ello, se utilizó la observación y la elaboración de instrumentos. Más exactamente, se usaron cuestionarios y entrevistas para la recopilación de datos. A continuación, se ampliará con más detalle este proceso y sus componentes. 


\subsection{Informantes}

Los informantes fueron (a) los alumnos de una sección de Comunicación y (b) la totalidad de docentes del curso, en el semestre 2016II, en una universidad privada de Lima. En seguida, con la Tabla 6 y la Tabla 7, se expondrán los perfiles de ambos grupos, respectivamente, con datos recuperados a partir de la encuesta con mayoría de participantes.

Tabla 6

Perfil de los Alumnos Participantes

\begin{tabular}{|c|c|c|}
\hline Edad promedio (años) & 18.75 & \\
\hline \multirow{2}{*}{ Género (\%) } & Mujeres & 67,9 \\
\hline & Varones & 32,1 \\
\hline \multirow[t]{3}{*}{ Carreras (\%) } & Nutrición & 89,3 \\
\hline & Medicina Humana & 7,1 \\
\hline & Terapia Física & 3,6 \\
\hline \multirow[t]{3}{*}{ Ciclo actual (\%) } & Primero & 82,1 \\
\hline & Segundo & 3,6 \\
\hline & Tercero & 14,3 \\
\hline \multirow[t]{2}{*}{ Repitencia (\%) } & Primera vez & 92,9 \\
\hline & Segunda vez & 7,1 \\
\hline
\end{tabular}


Tabla 7

Perfil de los Docentes Participantes

\begin{tabular}{llc}
\hline Edad promedio (años) & & 35.5 \\
Género (\%) & Mujeres & 62,5 \\
& Varones & 32,1 \\
Carrera de pregrado (\%) & Educación & 50 \\
& Lingüística & 25 \\
& Literatura & 12,5 \\
& Lengua y Literatura & 12,5 \\
Años de experiencia & & 6.6 \\
en docencia universitaria & & \\
(promedio) & & 62,5 \\
Dictado en Comunicación (\%) & Primera vez & 37,5 \\
& Segunda vez & 75 \\
Capacitación en E-learning & Recibió & 25 \\
en los últimos dos años & No recibió & \\
\hline
\end{tabular}

\subsection{Instrumentos de análisis}

Los instrumentos empleados fueron dos tipos de cuestionarios aplicados, con adaptaciones, a los dos tipos de informantes. Asimismo, se realizó entrevistas a tres estudiantes seleccionados según el nivel de logro que alcanzaron en la Unidad 1 y a dos docentes del equipo de Comunicación. En todos los casos, se cursó un documento de consentimiento informado y el correspondiente compromiso de confidencialidad. 


\subsubsection{Cuestionarios}

En total, se aplicó cuatro cuestionarios diferentes: (a) Encuesta Alumnos Hábitos Letrados en Línea (AH), (b) Encuesta Alumnos Quip (AQ), (c) Encuesta Docentes Hábitos Letrados en Línea (DH), y (d) Encuesta Docentes Quip (DQ). Como se apreciará en la Tabla 8, para el planteamiento de criterios y alternativas de respuesta, estos demandaron ciertos insumos que fueron adaptados de acuerdo con la población analizada. Asimismo, en la Tabla 9, se observará la asociación de funciones, ventajas y desventajas que dio como resultado los indicadores empleados en los cuestionarios. Las encuestas empleadas en los diagnósticos se aplicaron en noviembre de 2016 a través de cuatro Cuestionarios de Google con preguntas de opción múltiple. Luego, se tabularon en Microsoft Excel para su análisis con indicadores, respuestas preponderantes y valor en porcentajes.

Tabla 8

Insumos de los Cuestionarios

Cuestionarios Insumos

AH Diagnóstico Acerca de los Hábitos Letrados en la Red y el Nivel de Desempeño en Redacción de los Alumnos de una Universidad Privada del Perú.

- Precuestionario sobre hábitos letrados en línea.

AQ - Precuestionario sobre el uso de Quip en el trabajo académico 1 (TA1).

DH Diagnóstico Acerca de los Hábitos Letrados en la Red y el Nivel de Desempeño en Redacción de los Alumnos de una Universidad Privada del Perú.

DQ

- Plenario de reuniones de coordinación. 


\section{PRÁCTICAS LETRADAS EN LÍNEA: LA APLICACIÓN DE QUIP EN LA REDACCIÓN DE ESTUDIANTES UNIVERSITARIOS}

\section{Tabla 9}

\section{Quip: Funciones Asociadas con Ventajas y Desventajas}

Funciones Ventajas Desventajas

1. Chat con los usuarios del Edición de un mismo texto con otras documento o carpeta

personas en tiempo real. $(4,7,8)$

2. Sala de chat también fuera del documento

3. Administración de documentos y carpetas (crear nuevo, adicionar, compartir, copiar, mover, ordenar, asignar colores)

4. Opción de compartir el documento con usuarios y no usuarios de Quip

5. Visualización de los documentos en lista y en cuadrícula con marcas de editores y actualizaciones

6. Notificaciones al dispositivo cuando hay cambios en el documento

7. Procesador de texto (letra, tamaño, viñetas, inserción de imágenes y tablas, etc.)

8. Edición offline (sin conexión a la red) que se actualiza al iniciar sesión.

9. Exportar el documento a formatos de procesador de texto (PDF, Word, Excel, etc.)

10.Añadir integración (exportar el documento a Twitter, Dropbox, Gmail, Email, etc.)

11.Bandeja de entrada (solicitudes, recibidos, destacados, sin leer, leídos, mensajes directos, privados, creados por mí) profesor. $(1,2,5,6,11)$ $4,6,11)$ $4,5,6,7,8,9,10,11)$ borre lo que escribió la otra. (7)

Grabación automática documentos. $(3,5,6,8,11)$ $7,9)$ $(3,4,6,7,9,10,11)$ instalar la aplicación. (15) $17,22)$
Dificultad para instalar la aplicación en los dispositivos. $(14,15)$

Monitoreo y retroalimentación más directa y constante por parte del

Comunicación con otros colaboradores en el chat para acordar los cambios en el documento. (1, 2,

Problemas para completar la membresía. $(14,15)$

Imposibilidad de que dos personas editen simultáneamente un mismo párrafo, lo cual retrasa el trabajo. $(15,18)$

Reemplazo del uso de soportes físicos tradicionales (papel). (1, 2, 3,

Imposibilidad de que dos personas editen simultáneamente un mismo párrafo, lo cual asegura que una no

de

Opciones de edición de texto (tamańo, tipo de letra, vińetas, tablas) muy básicas. (18)

Opciones de edición de texto (tamaño, tipo de letra, viñetas, tablas, imágenes) difíciles de usar. (18)

Inclusión en el chat de las conversaciones y los cambios que se realiza en el texto, lo cual es confuso. $(16,17,22)$

Inserción de imágenes, videos, tablas, etc. en el texto. $(1,2,4,6$,

Recepción de muchas notificaciones de actividad en el documento, lo cual es confuso. $(16,17,22)$

Utilización en todos los dispositivos.

Utilización desde un navegador, sin

Exportación de documentos a otros formatos (PDF, Word, etc.). (20)

Visibilidad del historial de cambios que se realiza en el documento. (16,

Posibilidad de escritura offline, es decir, sin conexión a la red. (19)

Posibilidad de escribir en solitario sin necesidad de incluir a otras personas. $(14,18)$

Recepción de notificaciones de actividad en el documento. $(16,17,22)$ 
Cabe resaltar la importancia de un diagnóstico antecedente para la elaboración de los cuestionarios $\mathrm{AH}$ y $\mathrm{DH}$. Este se realizó a partir de cuestionarios, una pregunta de encuesta y una evaluación del proceso de redacción de alumnos del curso de Nivelación de Lenguaje de una universidad privada del Perú. Dicha población fue muy similar a la de Comunicación en cuatro aspectos: (a) pertenencia a la misma universidad; (b) ubicación en los primeros ciclos de la malla curricular; (c) textos expositivos como productos de la redacción colaborativa y (d) similar rango de edades de los participantes.

En este primer diagnóstico se utilizó criterios propios, además de algunos sugeridos por Rocha (s.f.); Gómez, Roses y Farías (2012); Cheicher y Donolo (2013); y Carrera, Sapién y Piñón (s.f.), que los emplearon para evaluar el uso de las redes sociales y su aplicación en el aprendizaje, respectivamente. Los instrumentos de recopilación de datos (cuestionarios, exámenes y rúbricas) fueron presentados y aprobados por la profesora del curso Investigación y Práctica Educativa 2, Mg. Elizabeth Flores Flores, quien certificó su validez en el contexto del Plan Especial de Licenciatura en Educación para el Desarrollo, durante el semestre 2015-II. Asimismo, este diagnóstico fue trascendente para adoptar la decisión de analizar Quip como una herramienta didáctica integradora de las prácticas letradas en línea.

\subsubsection{Entrevistas}

Se entrevistó, en cuanto al grupo de alumnos, a tres de ellos cuyo promedio en la Unidad 1 del curso los ubicó, respectivamente, en cada uno de los tres niveles de logro según las rúbricas por competencia empleadas: básico, en proceso y logrado. Por otro lado, en el grupo de docentes, se entrevistó a dos de ellos, elegidos porque cada uno usó una plataforma de 
PRÁCTICAS LETRADAS EN LÍNEA: LA APLICACIÓN DE QUIP EN LA REDACCIÓN DE ESTUDIANTES UNIVERSITARIOS

escritura colaborativa distinta para el desarrollo de las actividades del curso en la Unidad 1.

\section{Vínculos y Posibilidades a partir del Diagnóstico de los Hábitos Letrados en Línea}

A continuación, se expone los vínculos y posibilidades para la redacción establecidos a partir del diagnóstico del uso de Quip, realizado tanto a docentes como a estudiantes. Los resultados propuestos son producto de la tabulación rigurosa de los datos aportados por los cuestionarios $\mathrm{AH}$ y DH. Además, se asocian bajo los criterios que dichos instrumentos establecieron.

\subsection{Sobre el acceso a internet}

El ingreso de docentes y alumnos a la red es total. En cuanto a la finalidad de acceso a las redes, ambos de diferencian: mientras que los docentes consideran como finalidad principal el aprendizaje académico, los alumnos le dan prioridad a la comunicación con sus contactos. Asimismo, en cuanto a las ventajas de acceso, los docentes consideran la reducción del costo del aprendizaje académico y el desarrollo de actividades laborales como prioritarios, mientras que compartir información multimedial es la ventaja detectada por los estudiantes. Esto evidencia que para los docentes la red implica condiciones provechosas como instrumento de uso académico, mientras que, para los alumnos, el uso de la red genera beneficios asociados con las características de la propia red.

Con respecto al soporte desde el que se accede, predomina en ambos grupos el smartphone de uso personal, lo cual implica que comparten 
el mismo conocimiento de la tecnología y el acceso económico a esta. Sin embargo, en cuanto a las horas de acceso se ha generado datos reveladores: en un día de clase habitual, la mayor parte de los docentes accede a la red hasta $6 \mathrm{~h} \mathrm{u} 8 \mathrm{~h}$, mientras que la mayoría de alumnos lo hace hasta $3 \mathrm{~h}$ diarias. Esta diferencia se mantiene también en el acceso del fin de semana, cuando los primeros alcanzan hasta $8 \mathrm{~h}$ de acceso, mientras que los segundos llegan a 6 h. Estos datos cuestionan la idea generalizada de que los estudiantes "viven" en Internet. Son los profesores quienes pasan más tiempo en Internet, aunque, como se apreciará, realizando labores y siguiendo intereses distintos.

\subsection{Sobre las redes sociales}

El uso de las redes sociales por parte de docentes y alumnos es total. En cuanto a su finalidad de uso, tiene primacía, para los docentes, la búsqueda de información sobre hechos actuales, y, en segundo orden, la posibilidad de contactar con amigos e interactuar con los alumnos para el desarrollo de trabajo académico. Por su parte, los estudiantes privilegian dos finalidades: la comunicación con los contactos y la búsqueda de información sobre hechos actuales. Esto enmarca una diferencia, debido a que los docentes usan las redes como fuente noticiosa, y los alumnos, como medio de interacción social, lo cual revela distintos intereses. Sin embargo, un aspecto de coincidencia, en segundo orden, es la búsqueda de información de hechos actuales, que puede ser aprovechada para sugerir información de las redes como motivo de discusión en la prelectura. Por otro lado, con respecto a la ventaja principal, docentes y alumnos coinciden en que las redes son importantes por la rapidez con que circula la información frente a otros medios de la red. 
Asimismo, con respecto a la obtención de una cuenta en una red social específica, docentes y alumnos coinciden en ser usuarios mayoritarios de Facebook. Esta coincidencia se puede aprovechar para vincular a ambos grupos en un entorno provechoso para generar estrategias didácticas interactivas. Por otro lado, con respecto al uso frecuente de aplicaciones, Facebook aparece nuevamente como una coincidencia. Aunque también surge como opción, del lado de los alumnos, la preferencia por las redes audiovisuales como Youtube, lo cual abre la posibilidad de usar este canal con fines didácticos, a través de tutoriales de redacción o videos que motiven al debate de fuentes.

\subsection{Sobre la mensajería instantánea}

El uso de la mensajería instantánea es total en el caso de los docentes, y mayoritario, en el de los alumnos (96,4\%), lo cual implica una coincidencia, debido al escaso margen de diferencia. Con respecto a la finalidad principal de uso, ambos grupos coinciden en la importancia de estar en comunicación con sus contactos y amigos. Por otro lado, con respecto a la ventaja principal, los docentes privilegian la rapidez y la funcionalidad de las aplicaciones por sobre otros medios de comunicación tradicionales como el teléfono y los mensajes del celular, y, en segundo orden, valoran la posibilidad de compartir información multimedial con sus contactos. Por su parte, los alumnos también valoran la rapidez, pero por sobre otros medios de comunicación de la red, y mantienen como segunda preferencia el compartir información multimedial.

De igual modo, se observa que, en cuanto a las ventajas, se genera una diferencia notable: los alumnos comparan la mensajería instantánea con otros medios de la propia red, mientras que los docentes lo hacen con 
los medios tradicionales, pues, para ellos, estos gozan de mayor vigencia. Asimismo, se aprecia una coincidencia en cuanto a la segunda ventaja: compartir información diversa o multimedial. Esta semejanza sugiere posibilidades didácticas, pero se debe considerar el punto de referencia de la primera ventaja.

Es decir, emplear la mensajería instantánea con fines didácticos puede vincular ámbitos con diferente grado de apertura: el docente puede preservar, para la mensajería instantánea, los mismos códigos de la comunicación tradicional (por ejemplo, mayor grado de privacidad: admisión solo de contactos conocidos, restricción a temas domésticos o personales) mientras que el alumno, al considerar la mensajería instantánea en contraste con otros medios de la red, la aprecia como un medio con menor grado de privacidad, es decir, donde se permite la admisión de contactos recientes, la apertura de temas genéricos, el uso coloquial del lenguaje, la frivolización de contenidos, en general, la "cháchara" denostada por Cassany (2012). Sin embargo, bajo una estrategia didáctica de reglas fijas y bajo un entorno instruccional adecuado, se puede emplear la mensajería como una estrategia.

Finalmente, en lo que concierne a la obtención de cuentas de mensajería instantánea, existe una coincidencia plena en ambos grupos: WhatsApp es la primera opción, y la segunda, Messenger de Facebook. Ocurre de modo similar con respecto al uso de una aplicación frecuente. Esta coincidencia es aprovechable para realizar labores de coordinación, revisión de fuentes y planificación, es decir, subetapas de la preescritura. Además, a pesar de que existe una respuesta negativa en cuanto al uso de la mensajería instantánea por parte de los alumnos, este margen es escaso e inexistente en el grupo de los docentes. 


\section{PRÁCTICAS LETRADAS EN LÍNEA: LA APLICACIÓN DE QUIP EN LA REDACCIÓN DE ESTUDIANTES UNIVERSITARIOS}

\subsection{Sobre las prácticas letradas en línea}

\subsubsection{Lectura}

Existe una diferencia escasa en cuanto a la participación de docentes (100\%) y estudiantes (89,3\%) en las prácticas letradas en línea. Asimismo, ocurre una diferencia con respecto a la finalidad principal: los docentes se decantan, como primera opción, por la búsqueda de información para realizar labores académicas propias, y como segunda, el desarrollo de actividades de enseńanza como la corrección de trabajos, mientras que los alumnos se enfocan en la búsqueda de información sobre temas de interés no académico, en primer lugar, y en segundo, en la búsqueda de información para realizar tareas académicas. Si bien existe una diferencia en cuanto al objeto de búsqueda, no ocurre lo mismo con la intención. Para explotar esta coincidencia no se sugiere cambiar los hábitos de ninguno de los grupos, pero sí buscar un punto de encuentro en torno a la búsqueda de información como actividad vértice. De acuerdo con ello, se propone la motivación mediante la búsqueda de temas y fuentes de divulgación como puerta de ingreso a los textos académicos. Para ello, se requiere explotar la segunda finalidad del docente: el desarrollo de las actividades de enseñanza, las cuales pueden incluir estos temas como parte de las prácticas letradas académicas.

Por otro lado, en lo que se refiere a la ventaja principal, se produce una coincidencia de docentes y alumnos. Ambos procuran la obtención de la mayor cantidad de información disponible. Sin embargo, se diferencian en la segunda opción, que para los docentes es la posibilidad de descargar información a sus dispositivos, y para los alumnos, la gratuidad de la información. Esto quiere decir que el profesor se mantiene en la 
conservación de las fuentes, exige cantidad y la atesora; mientras que los alumnos también valoran la disponibilidad, pero, también la gratuidad, debido a la dependencia económica de sus padres.

En relación con la práctica de lectura frecuente, para los docentes es mayoritaria la lectura de información académica en formato electrónico (PDF, Epub, etc.) descargada de la red (artículos, tesis, materiales de estudio), seguido de la lectura de trabajos de alumnos para su corrección y de la lectura de publicaciones o comentarios de contactos en las redes sociales. En el caso de los alumnos, se privilegia la lectura de información académica en formato electrónico descargada de la red, lo cual implica una coincidencia con la práctica principal de los docentes. En cambio, la segunda opción de los alumnos vincula a dos prácticas al mismo nivel: la lectura de mensajería instantánea y la lectura de información no académica en formato electrónico descargada de la red.

En este contexto, Facebook desaparece de la lectura frecuente de los alumnos y surge WhatsApp como alternativa. Esta es una oportunidad si se considera la afinidad entre las segundas opciones de ambos grupos: la lectura de trabajos de alumnos por parte del docente puede vincularse con la lectura de mensajería instantánea, si es que alguna etapa de la redacción involucra el uso de la mensajería instantánea. Asimismo, contra lo que se puede pensar, Facebook como red social es una mayor fuente de lectura para los docentes que para los alumnos, que se enfocan en la mensajería instantánea. Finalmente, en lo que concierne al dispositivo de uso frecuente, existe coincidencia en el uso de los smartphones de uso personal en ambos grupos.

Por otro lado, con respecto a las aplicaciones de redes o mensajería vinculadas con la lectura, el uso de Facebook configura una coincidencia; sin embargo sorprende la aparición de una opción menos generalizada entre 
las alternativas: Whatpad, plataforma de lectura y publicación de relatos. Como se aprecia, Facebook se impone como la aplicación de red social que permite la lectura en los dispositivos. WhatsApp se mantiene como la segunda opción para los alumnos, pero como tercera para los docentes. Asimismo, la aparición de Whatpad como opción de los alumnos puede promoverse como un vínculo en cuanto a la lectura de textos creativos, actividad no exenta de los intereses y del perfil de los docentes, formados en las Humanidades y en las Ciencias de la Educación.

En cuanto a las aplicaciones diseñadas exclusivamente para leer, existe coincidencia en ambos grupos en el uso principal de Acrobat Reader (PDF) seguido de iBooks (IOS). Sin embargo, estas elecciones revelan el uso de lectores genéricos en ambos grupos, los cuales no buscan aplicaciones especializadas y permanecen con las que sus dispositivos traen predeterminadas. Una razón posible en la elección de Acrobat Reader son las funciones más avanzadas para el dispositivo móvil de uso general en los dos grupos. Sin embargo, el soporte no es una variable en este criterio.

Con respecto a la participación en comunidades de lectores, los docentes prefieren interactuar, mayoritariamente, en comunidades de educadores en diversas ramas del conocimiento, y en segundo término, en comunidades de comentarios sobre textos literarios o científicos de autores editados y reconocidos. En cambio, la mayoría de alumnos participa en comunidades de comentarios sobre textos literarios o científicos de autores editados y reconocidos, y, en segundo rango, en comunidades de lectores y escritores que comparten obras propias. La diferencia puede deberse a los roles que cumplen ambos grupos en la enseñanza-aprendizaje; sin embargo, en distinto orden en ambos grupos, aparece el interés de participar en comunidades que comentan textos literarios y científicos. Esto abre una posibilidad de proponer lecturas que impliquen la visita a dichas 
comunidades de obras compartidas. Asimismo, es pertinente considerar las comunidades de obras literarias propias como motivación para la práctica de la lectura interpretativa y la escritura creativa.

Finalmente, en cuanto a la negativa de practicar la lectura en la red, las razones son inexistentes para el grupo de docentes, y son reales, pero indeterminadas, para los estudiantes. Solo después de la opción "otra no mencionada" surge la carencia de conocimientos para usar las aplicaciones de lectura en la red como motivo determinado. La indeterminación de la opción de disidencia en el caso de los alumnos puede deberse a la falta de precisión de la encuesta para establecer una alternativa válida, lo cual debe afinarse. Ante este panorama, se evaluó el uso de audiolibros como una práctica afín a la lectura. La negativa en ambos grupos frente a esta actividad fue mayoritaria; sin embargo, en la minoría de ambos participantes, se determinó iBooks como audiolibro de uso frecuente. Se considera que, a pesar de estos resultados, es posible explorar la opción del audiolibro a partir de la autoinstrucción o de una capacitación institucional del departamento de tecnología en cuanto al uso de los Podcast. Esta sugerencia se ampara en la disponibilidad que tenga el iPad como dispositivo institucional, el cual incluye a iBooks y Podcast como aplicaciones predeterminadas.

\subsubsection{Escritura}

Existe una breve diferencia, aunque sí una participación mayoritaria por parte de docentes $(87,5 \%)$ y alumnos $(71,4 \%)$. La finalidad principal también resulta diferente. Para los docentes, la primera opción es redactar tareas académicas propias, $y$, en segundo plano, interactuar con contactos personales o alumnos en la red con fines de asesoría. Estas finalidades marcan diferencia con las de los alumnos, quienes prefieren escribir para 
comunicarse con sus contactos en las redes, y relegan la opción de redactar tareas académicas. Sin embargo, el punto de contacto puede ser la segunda opción docente: la comunicación en las redes, no entendidas plenamente como tareas académicas, sino con mayor flexibilidad, pueden, en el mejor de los casos, adoptar la forma de foros de discusión que apoyen las etapas de prelectura o preescritura, o en el rol más básico, actuar como repositorio del avance del curso, trabajos, capturas de pizarra, coordinación del curso, todas ellas actividades en que está involucrada la escritura digital, etc.

Por otro lado, con respecto a la ventaja predominante, para los docentes, es de primer orden que sus escritos se publiquen más rápido que en los textos físicos, y, en segundo orden, es valiosa la posibilidad de escribir colaborativamente por medio de aplicaciones. Del lado de los alumnos, la ventaja mayoritaria es la expresión libre de ideas, y, en tercera opción, figura la escritura colaborativa. Estas claras diferencias evidencian que la rapidez de publicación es preferida por los docentes como una superación de los medios físicos y presenciales que han sido sus referentes inmediatos de formación, según el promedio de sus edades (35,5 años). Para el alumno, en cambio, se cumple más la función expresiva, debido a que la red termina siendo un medio de contacto inmediato, efímero y espontáneo (esto es respaldado por el uso preferente de la mensajería instantánea).

Sin embargo, hay un punto en común: la preferencia por la celeridad. Esta puede considerarse una cualidad distintiva de las prácticas que puede apoyar ciertos aspectos del curso que involucren expresiones rápidas y la obligación de ser concisos: hablamos de la coordinación de actividades más allá del papel impreso y del recojo de opiniones en las negociaciones alumno-docente. Asimismo, esta inmediatez puede ser útil en la parte inicial del proceso de redacción, cuando se trata de discutir la pertinencia de un tema de redacción o de debatir sobre cómo debe entenderse una consigna 
de redacción. Con respecto a la escritura colaborativa, es importante que el docente comunique a sus alumnos las funciones y ventajas a fin de que pueda percibirse como una herramienta ventajosa.

Con respecto a la práctica de escritura más frecuente, existe una diferencia radical que marca un límite generacional que puede ser modulado, sin necesidad de ser abolido, por la vinculación entre los EVA y los EPA de docentes y alumnos. Para los primeros, es preferente la escritura académica en formato electrónico Word, PDF; para los segundos, es relevante la escritura en WhatsApp como aplicación genérica. Asimismo, los dispositivos usados configuran sí una coincidencia: se trata, como en la mayoría de actividades anteriores, del smartphone de uso personal. Este permite el uso de aplicaciones generales de escritura. La preferida de los docentes es Facebook, mientras que, para los alumnos, es WhatsApp. Se observa que la opción del profesor implica la elaboración de mensajes menos espontáneos que los del alumno.

En lo que concierne a las aplicaciones diseñadas exclusivamente para la escritura, los docentes, prefieren usar los procesadores tradicionales como Word y el block de notas disponibles de fábrica en sus dispositivos. En este rango, Quip aparece como tercera opción. Estas opciones generan plena coincidencia con los hábitos de los alumnos. Esta puede ser aprovechada para potenciar la opción de Quip a partir de la exportabilidad de sus documentos a formato de Word, y, como se apreciará en la encuesta AQ, existe complementariedad entre Quip y el block de notas. Sin embargo, esta coincidencia también pone de manifiesto la preferencia por los procesadores de textos tradicionales, que pueden ser empleados, al igual que Quip, un procesador más reciente, en todos los dispositivos.

Asimismo, con respecto a la preferencia por comunidades de escritura, hay equivalencia entre dos opciones de los docentes: comunidades 
de educadores y comunidades de comentarios sobre textos literarios o científicos reconocidos. A pesar de la diferencia, en segundo orden, existe una afinidad. Esto se debe a que los alumnos, como primera opción, admiten participar de comunidades de comentarios sobre textos literarios o científicos reconocidos.

Finalmente, en lo que concierne a la opción negativa a escribir en la red, los docentes arguyen que no les parece tan funcional o placentero como hacerlo por otros canales físicos de escritura (manuscritos, o libros, revistas y periódicos impresos). Esta postura se diferencia de la de los alumnos, cuya razón principal es indeterminada, pero le sigue el desconocimiento sobre cómo utilizar las aplicaciones de escritura en la red. A pesar de la diferencia, existen razones en común. Los resultados revelan que el componente de la cultura del libro impreso es fuerte en el caso de los docentes, lo cual implica la transmisión de un conocimiento tradicional por medio de canales físicos. Aunque no sea evidente, en este sentido, también se encuentra la disyuntiva del alumno que no escribe en la red, puesto que, además de las razones no conocidas, no ha recibido de la red el conocimiento necesario para usar las aplicaciones, que es una práctica que sigue la modalidad entendidodiscípulo, ahora trocado en sugerencias de aplicaciones y tutoriales de uso de recursos virtuales, dirigidos por las empresas, en el primer caso, y por usuarios de las aplicaciones, en el segundo.

\subsection{Sobre el uso de los EVA (aula virtual) y EPA (plataformas virtuales en general)}

En cuanto al uso frecuente del aula virtual, se presenta una coincidencia parcial. El uso de los docentes es total, mientras que el de los estudiantes es mayoritario. Asimismo, con respecto a la finalidad principal 
de esta herramienta institucional, existe una coincidencia total en cuanto a las funciones de descarga de materiales de clase y de acceso a la información sobre los cursos. Sin embargo, ninguna de las partes privilegia el contacto con el profesor o compañeros. Para docentes y alumnos el aula virtual es un repositorio de recursos y de administración del curso, a pesar de los recursos de foros, blogs y wikis que esta ofrece. Cabe preguntarse a qué se deberá esta limitación: ¿̨falta de dinamismo, interacción, entorno atractivo, funcionalidad, utilidad?

En lo que concierne a la función de uso frecuente en el aula virtual, esta focaliza la de consulta (unidades, semanas). Para los docentes, la función de wiki no se considera una opción viable, y, en el caso de los alumnos, esta ocupa una cuarta alternativa. Estas coincidencias revelan el uso administrativo que se le da al aula virtual, pero surge el cuestionamiento acerca del desuso de las wikis institucionales. La explicación puede plantearse en dos escenarios: alguna aplicación de escritura colaborativa atrae las preferencias de docentes y alumnos; o simplemente las wikis del aula virtual son poco empleadas en los cursos por parte de los docentes-administradores.

Por otro lado, en cuanto a la preferencia de plataformas virtuales de uso académico, se presenta una clara diferencia. Los docentes expresan la primacía de las wikis fuera del aula virtual versus la preponderancia que le otorgan los estudiantes a las funciones de esta herramienta institucional. $\mathrm{Al}$ respecto, la diferencia es radical, pero no obstructiva, debido a que la preferencia del alumno por el aula virtual puede dar la opción del uso de las wikis. Sin embargo, sí existe una barrera en cuanto a la integración directa de las wikis de uso en los EPA y el aula virtual más allá de los enlaces o embebidos con que se puede generar un hipervínculo. Asimismo, en ambos casos, se evidencia un escaso uso de las redes sociales con finalidad académica entre las plataformas virtuales comparadas con las opciones de aula virtual y wikis. 
Finalmente, ante la consulta sobre la preferencia de una plataforma virtual no educativa empleada para fines educativos, la primacía, en el caso de los docentes, es otorgada a las wikis, y, en segundo orden, a las redes sociales. En cambio, los alumnos privilegian el uso de las redes sociales, y, en segunda instancia, las wikis. Esta diferenciación evidencia la preferencia de los docentes por las wikis de acceso libre. Ello demuestra el efecto provechoso de la capacitación en el curso de Comunicación, en el cual la mitad del equipo era bisońo en la utilización de Quip y de otras plataformas de escritura colaborativa. En el caso de los alumnos, sus elecciones revelan mayor fiabilidad en la plataforma que les es conocida y que emplean con mayor frecuencia.

\subsection{Sobre la aplicación de las plataformas virtuales EVA y EPA en la redacción de un texto en el contexto del curso de Comunicación}

En cuanto a la fase de revisión de fuentes, predomina, para los docentes, el uso de las wikis no institucionales, y en segundo orden, el aula virtual. En cambio, los alumnos revelan el sentido contrario: prefieren el aula virtual para revisar las fuentes y, en segundo orden, el uso de aplicaciones como Quip. Esta diferencia revela la importancia que tiene para los alumnos las funciones administrativa y de descarga de clases. Como se evidencia en las entrevistas, para ellos, esta fase de la redacción es limitada para el uso de las wikis. Una situación similar se presenta en la etapa de planificación. Para los docentes, las wikis configuran una primera opción. Sin embargo, para los alumnos, el aula virtual es una alternativa mayoritaria, seguida por las wikis en segundo orden. Esta diferencia expone la limitación de las wikis, debido a los problemas de inserción de imágenes que serán respaldadas por las entrevistas a alumnos y docentes. 
El panorama vira hacia la aceptación y primacía creciente del uso de las wikis en las etapas de redacción de la versión preliminar. Los docentes declaran empleo total, y los alumnos una alta preferencia El mismo escenario se presenta en las etapas de retroalimentación, reescritura, presentación del trabajo y comunicación de la evaluación. En general, estas coincidencias expresan que las wikis han ganado terreno en las etapas de la escritura y posescritura. Esta información será respaldada por las encuestas AQ, DQ y por las entrevistas a alumnos y docentes.

\section{Vínculos y Posibilidades a partir del Diagnóstico del Uso de Quip}

A continuación, se expondrá los vínculos y posibilidades para la redacción establecidos a partir del diagnóstico del uso de Quip, realizado tanto a docentes como a estudiantes. Los resultados propuestos son producto de la tabulación rigurosa de los datos aportados por los cuestionarios AQ y DQ. Igualmente, estos resultados se asocian bajo los criterios que dichos instrumentos establecieron.

\subsection{Aspectos generales (acceso, ventajas y desventajas)}

En cuanto al soporte de Quip preferido existe una coincidencia parcial. Los docentes emplean, en el mismo rango, laptops y smartphones, y los alumnos prefieren el último de estos dispositivos. Esta coincidencia pone de manifiesto el apego de los docentes a los soportes más tradicionales. Por otro lado, con respecto a la cantidad de horas de acceso en un día de clase de Comunicación, existe una coincidencia evidente en el acceso de hasta $3 \mathrm{~h}$. Asimismo, en lo que concierne a las horas de acceso a Quip en la semana sin contar las clases de Comunicación, las actividades de los docentes demandan 
hasta $6 \mathrm{~h}$, mientras que el tiempo de los alumnos es inferior (hasta dos horas). Esta diferencia evidencia el mayor trabajo del docente en las labores de corrección de los trabajos realizados en la plataforma.

Por otra parte, en lo que se refiere a la valoración de la comunicación docente en Quip, los docentes y alumnos coinciden en la calificación de buena. Sin embargo, en cuanto a la característica de mayor ventaja para la redacción en general, se presenta una discordancia: los docentes privilegian el monitoreo y retroalimentación directos y constantes, y los alumnos le otorgan a esta ventaja un segundo orden, por debajo de la escritura colaborativa en tiempo real, aspecto básico de Quip. Esta diferencia, más allá de las preferencias, muestra el reconocimiento de roles habitualmente establecidos en la didáctica de la redacción, sin mayor dinamismo que los optimice.

En cuanto a la característica desventajosa de Quip en la redacción general se presenta una diferencia parcial. Los docentes opinan que las opciones de edición de texto son difíciles de usar, y los alumnos, que estas son muy básicas. Sin embargo, ambos se enfocan en las opciones de edición de texto como un limitante. La percepción del docente recae en la capacitación que le falta para dominar las opciones difíciles de edición; el alumno, más familiarizado con los soportes virtuales en general, considera básicas las opciones en comparación con otras aplicaciones. Asimismo, desde ambas posturas, esta limitación se emparenta con las dificultades en la revisión de fuentes y planificación, es decir, la preescritura, señaladas en las encuestas $\mathrm{AH}$ y $\mathrm{DH}$, y serán respaldadas en este diagnóstico y por las entrevistas.

De otro lado, con respecto a la ventaja principal enfocada en la redacción individual, la realización (del docente) y la recepción (del alumno) del monitoreo y retroalimentación más directa y constante mediante el chat de Quip entablan coincidencia plena. Es notable la importancia que 
docentes y alumnos le otorgan a la opción de comunicación inmediata, el chat, el cual comparte funciones con la mensajería instantánea, debido a las notificaciones que el programa realiza en los dispositivos. Asimismo, con respecto a la desventaja mayor en este tipo de redacción también existe gran coincidencia. El reclamo se enfoca en las limitaciones que imponen las opciones de edición de texto (tamaño, tipo de letra, viñetas, tablas), que, para ambos grupos, resultan ser son muy básicas. Esta coincidencia hace eco de las dificultades expresadas con respecto a la etapa de preescritura

Finalmente, enfocados en la redacción grupal, la ventaja principal para los docentes es la realización del monitoreo y la retroalimentación directa y constante, mientras que los estudiantes privilegian la característica fundamental de Quip: la escritura colaborativa en tiempo real. Ahora, del lado de las desventajas en este tipo de redacción, para los docentes resulta confuso el uso del chat, debido a que incluye tanto las conversaciones como los cambios del documento. La alternativa de los alumnos, en cambio, se enfoca en un aspecto más práctico y ligado con su rol en la redacción: estos consideran una desventaja la imposibilidad de editar un mismo párrafo, debido a que retrasa el avance del trabajo.

\subsection{Sobre la inclusión de Quip en las fases de la redacción}

En lo que concierne a la valoración de Quip en todas las etapas, por parte de los alumnos, esta es calificada como buena en todas las etapas. En relación con la etapa de la revisión de fuentes, los docentes han resaltado, equitativamente, seis funciones de Quip: (a) chat con los usuarios, (b) visualización del documento en lista o cuadricula y sus modificaciones, (c) envío de notificaciones de cambios, (d) procesador de texto y (e) exportación a otros formatos. Del lado de los alumnos, la función destacada 
es la del chat. Esta coincidencia parcial pone en relevancia la función de chat y sus posibilidades: la opción privilegiada por el alumno en la revisión de fuentes atraviesa dos de las funciones mencionadas por los docentes. Esto se debe a que el chat es multifunción: aparece en las modificaciones de la visualización y en las notificaciones de cambios, que son usuales para negociar la participación de los integrantes del grupo en los foros que puede elaborarse.

En lo concerniente a la etapa de la planificación, la ventaja para los alumnos se focaliza en la administración de documentos y carpetas. Esto se da en el mismo rango que la visualización de los documentos en lista y en cuadrícula con marcas de editores y actualizaciones. Es decir, ellos privilegian la presentación o apariencia de la aplicación, así como la visibilidad en el control de los cambios.

En cuanto a la redacción de la versión preliminar, a los docentes les parece ventajosa la administración de documentos y carpetas, mientras que la función preferida por los alumnos es la comunicación por chat con usuarios del documento. Esta diferencia pone de manifiesto la importancia que le confieren los alumnos a la comunicación y contrasta con la atención del docente, centrada en la administración del documento (inclusión de usuarios nuevos en los grupos que ya están editando, organización de los documentos de sus grupos en carpetas). Se espera que, una vez familiarizado con la aplicación, el docente privilegie lo que el alumno requiere desde el primer momento: la comunicación por chat o la comunicación presencial que dirija su redacción.

Con respecto a la retroalimentación 1, docentes y alumnos coinciden en la importancia de la comunicación por chat con los usuarios del documento. A ello se agrega la segunda opción que el docente le confiere a la posibilidad de compartir el documento con usuarios y no usuarios de 
Quip. Esta coincidencia revela que la comunicación por el chat adquiere suma importancia para el alumno en la retroalimentación, la cual involucra las correcciones que opera el docente en el texto del cual es también usuario. Por el lado del docente, la opción de compartir el documento con usuarios o no de Quip permite invitar a integrantes de otros grupos a observar el texto de sus compañeros, lo cual favorece las actividades de coevaluación, y será potenciado en un diseño posterior de actividades.

En relación con la reescritura, existen diferencias marcadas. Para los docentes, es importante el chat con los usuarios del documento o carpeta, y el uso de la sala de chat fuera del documento aparece en segundo orden. En cambio, para el alumno, es trascendente la administración del archivo, el hecho de compartirlos, copiarlos y moverlos.

En torno a la retroalimentación 2 (evaluación) existe una coincidencia con respecto al uso del chat con los usuarios del documento o carpeta. En su perspectiva, dicho uso promueve la interacción con el docente. Este vínculo demuestra que la comunicación sigue siendo un elemento fuerte de Quip, especialmente para la revisión final por parte del docente y la explicación de las correcciones.

Finalmente, en cuanto a las ventajas de la calificación del trabajo grupal, la mayoría de docentes no empleó Quip. Muy distinto fue lo que el alumno esperó de esta fase: para él tiene una importancia radical mantener el chat como un medio para la comunicación de los resultados. Esta desvinculación en una etapa final del proceso evidencia que el docente está dejando de lado los aportes del chat del Quip en relación con la posibilidad de brindar explicaciones inmediatas sobre la calificación. Asimismo, el chat ayuda a visibilizar el trabajo de los alumnos, debido a que registra las modificaciones en el texto, lo cual hace más certero el calificar la participación. 


\section{PRÁCTICAS LETRADAS EN LÍNEA: LA APLICACIÓN DE QUIP EN LA REDACCIÓN DE ESTUDIANTES UNIVERSITARIOS}

\subsection{Sobre las estrategias de uso del aplicativo}

En el caso de los alumnos, se indagó sobre el uso mayoritario de aplicaciones complementarias. El resultado arrojó un 54,5\% de uso preferente. El tipo de complemento preferido por este grupo fue el procesador de texto. En este contexto, la aplicación privilegiada fue Word, seguida del block de notas preinstalado en los dispositivos usados para la redacción.

Asimismo, con respecto a la finalidad de Quip en la Unidad 1, surgió una coincidencia notable al considerar la aplicación como un espacio en el que es posible redactar colaborativamente. Esto evidencia que, para docentes y alumnos, Quip es una herramienta de redacción en proceso, más que un muestrario del producto final. Esta es una diferencia radical con respecto a las funciones del aula virtual valorados por estos grupos.

Por otro lado, un criterio considerado con especial interés fue el de posibilidad de reúso posterior. En este aspecto, la coincidencia fue mayoritaria por parte de los docentes $(83,3 \%)$ y alumnos $(86,4 \%)$, lo cual demuestra amplia confianza en la aplicación empleada. Este criterio se adaptó a una serie de variables, las cuales, en su totalidad resultaron coincidentes y, por tanto, favorables para la aplicación.

En cuanto a la razón de posible reúso, primó la mejora del trabajo grupal e individual, lo cual reafirma la confianza en la utilidad de la aplicación. Con respecto a la posibilidad de reúso para una tarea colaborativa, primó en ambos grupos la confianza en la función principal: la escritura colaborativa en tiempo real. En lo que concierne a la posibilidad de reúso para tarea individual, la coincidencia fue mayoritaria. Esto, además de la gran valoración, abre la oportunidad para implementar la propuesta de portafolio individual de Cassany (2012) asociada con el uso de los blogs. 
Sin embargo, en lo referente al reúso para otras tareas del curso no obligatorias, no hubo coincidencia: para los docentes la aceptación fue mayoritaria, no así por parte de los alumnos. Esta diferencia, por el lado de los alumnos, demuestra carencia de autonomía en el uso de la aplicación fuera del contexto del curso, y en el caso de los docentes, una posibilidad autónoma de realizar la transferencia de la capacitación en Quip a otros contextos distintos del trabajo planificado en coordinación. En el mismo sentido, el criterio de reúso para tareas de otros cursos resultó minoritario en ambos grupos. A pesar de que se trata de una coincidencia, esta demuestra la falta de autonomía para hacer la trasferencia del conocimiento sobre Quip a contextos distintos al original. Por último, en lo que concierne a la razón principal de la negativa de reúso, se produjo una coincidencia parcial entre docentes y alumnos en función de la preferencia por medios tradicionales como el papel.

Finalmente, en cuanto a la recomendabilidad de la aplicación al entorno académico, la coincidencia total reveló la altamente recomendable que resulta Quip para el entorno académico de ambos grupos, en el cual se incluyen compañeros de clase y de trabajo, y docentes. Asimismo, la recomendabilidad al entorno personal no académico también obtuvo una alta coincidencia en ambos grupos. Esto revela las altas posibilidades de generar efectos de transferencia en los entornos personales distintos a los académicos. Este dato se sustenta más adelante en las entrevistas a docentes y alumnos. 
PRÁCTICAS LETRADAS EN LÍNEA: LA APLICACIÓN DE QUIP EN LA REDACCIÓN DE ESTUDIANTES UNIVERSITARIOS

\section{Entrevistas}

Existe un amplio consenso entre alumnos y docentes acerca de las ventajas de Quip en las etapas de la redacción o textualización y la reescritura. En el caso de los alumnos, las ventajas de Quip asociadas son la de la escritura colaborativa en tiempo real y la del monitoreo del docente por medio del chat. En el caso de los docentes, en precisión del que empleó Quip, hay plena coincidencia con las opiniones del alumnado, y, en el caso del que empleó Google Docs, se menciona la posibilidad de brindar acceso a los grupos para que observen el trabajo de otros compañeros. Explorar esta posibilidad a partir de la opción de embebidos de Quip sería interesante.

Existe consenso entre docentes y alumnos en cuanto al enriquecimiento que supone Quip en la vinculación de los EVA y EPA. La mayoría de entrevistados hace eco de la posibilidad de Quip de ir más allá de su uso educativo, el cual no es intencional, por cierto. En estos términos, la aplicación propone una posibilidad de vincular las prácticas académicas y las personales. Es memorable la intervención de uno de los alumnos, quien mencionó que había "capacitado" a su padre para que empleara la aplicación en su trabajo, con sus colaboradores. El docente que usó Google Docs no mostró una característica específica y se enfocó en la utilidad y productividad de su aplicación.

A continuación, en la Tabla 10 y Tabla 11, se apreciará la codificación de respuestas de alumnos y docentes, respectivamente. 


\section{MIGUEL ÁNGEL MALPARTIDA}

\section{Tabla 10}

Respuestas de los Alumnos

\begin{tabular}{|c|c|c|c|c|c|c|}
\hline A & Etapa que apoyó & $\begin{array}{c}\text { Etapa que no } \\
\text { apoyó }\end{array}$ & $\begin{array}{l}\text { Influencia en } \\
\text { evaluaciones y } \\
\text { calificaciones }\end{array}$ & Familiarización & $\begin{array}{l}\text { Afinidad con } \\
\text { las prácticas } \\
\text { letradas en } \\
\text { línea }\end{array}$ & $\begin{array}{c}\text { Valoración de } \\
\mathrm{AH} \text { y AQ }\end{array}$ \\
\hline A1 & $\begin{array}{l}\text { Reescritura: } \\
\text { permite } \\
\text { reconocer los } \\
\text { errores en } \\
\text { la redacción } \\
\text { durante la } \\
\text { asesoría por } \\
\text { parte de los } \\
\text { docentes. }\end{array}$ & $\begin{array}{l}\text { Revisión } \\
\text { de fuentes } \\
\text { (preescritura): no } \\
\text { permite adjuntar } \\
\text { un Word o PDF } \\
\text { al trabajo, solo } \\
\text { imágenes de las } \\
\text { fuentes, lo que } \\
\text { demanda más } \\
\text { tiempo. }\end{array}$ & $\begin{array}{l}\text { Influyente: la } \\
\text { intervención } \\
\text { continua } \\
\text { generó mayor } \\
\text { puntaje en la } \\
\text { calificación } \\
\text { de las } \\
\text { evaluaciones } \\
\text { grupales. }\end{array}$ & $\begin{array}{l}\text { Familiaridad: } \\
\text { resulta más } \\
\text { eficiente que } \\
\text { Word, por } \\
\text { el guardado } \\
\text { automático y la } \\
\text { visibilidad del } \\
\text { trabajo. }\end{array}$ & $\begin{array}{l}\text { Afín EVA: } \\
\text { principalmente } \\
\text { con las } \\
\text { prácticas } \\
\text { letradas online } \\
\text { académicas. }\end{array}$ & $\begin{array}{l}\text { Estructura: } \\
\text { Extensas, } \\
\text { sumamente } \\
\text { específicas, } \\
\text { pero } \\
\text { minuciosas } \\
\text { para un mejor } \\
\text { análisis de las } \\
\text { expectativas } \\
\text { de los } \\
\text { alumnos } \\
\text { sobre esta } \\
\text { aplicación y } \\
\text { sus beneficios. }\end{array}$ \\
\hline A2 & $\begin{array}{l}\text { Textualización: } \\
\text { permite organizar } \\
\text { el avance } \\
\text { para recibir la } \\
\text { retroalimentación } \\
\text { del docente } \\
\text { a través de } \\
\text { comentarios o } \\
\text { cambios sobre el } \\
\text { escrito. }\end{array}$ & $\begin{array}{l}\text { Ninguna: todas } \\
\text { son apoyadas } \\
\text { significativamente. }\end{array}$ & $\begin{array}{l}\text { Influyente: } \\
\text { registra las } \\
\text { contribuciones } \\
\text { de los usuarios } \\
\text { al texto, lo } \\
\text { cual las hace } \\
\text { visibles para } \\
\text { el docente al } \\
\text { considerar la } \\
\text { participación. }\end{array}$ & $\begin{array}{l}\text { Familiaridad: } \\
\text { aplicable } \\
\text { en otros } \\
\text { cursos y fue } \\
\text { comunicable } \\
\text { en el entorno } \\
\text { familiar- } \\
\text { laboral. }\end{array}$ & $\begin{array}{l}\text { Afín EVA } \\
\text { y EPA: } \\
\text { desarrollo } \\
\text { de diversas } \\
\text { actividades, } \\
\text { más allá de las } \\
\text { académicas. }\end{array}$ & $\begin{array}{l}\text { Finalidad: fin } \\
\text { educativo y } \\
\text { autoreflexivo } \\
\text { sobre la } \\
\text { actividad en } \\
\text { la redes. }\end{array}$ \\
\hline A3 & $\begin{array}{l}\text { Textualización } \\
\text { y reescritura: } \\
\text { permite editar al } \\
\text { mismo tiempo } \\
\text { y trabajar con } \\
\text { mayor eficacia } \\
\text { y rapidez los } \\
\text { textos. }\end{array}$ & $\begin{array}{l}\text { Revisión } \\
\text { de fuentes } \\
\text { (preescritura): no } \\
\text { permite revisar } \\
\text { las fuentes en } \\
\text { conjunto como sí } \\
\text { ocurre de modo } \\
\text { físico. }\end{array}$ & $\begin{array}{l}\text { Influyente: se } \\
\text { guardan las } \\
\text { modificaciones, } \\
\text { lo cual hace } \\
\text { visible la } \\
\text { participación. }\end{array}$ & $\begin{array}{l}\text { Familiaridad: } \\
\text { es un medio } \\
\text { más sencillo de } \\
\text { procesador de } \\
\text { textos. }\end{array}$ & $\begin{array}{l}\text { Afín EVA y } \\
\text { EPA: supera } \\
\text { el ámbito } \\
\text { educativo, } \\
\text { debido a que } \\
\text { la opción de } \\
\text { escritura en } \\
\text { tiempo real es } \\
\text { multisoporte. }\end{array}$ & $\begin{array}{l}\text { Finalidad: } \\
\text { identificación } \\
\text { del promedio } \\
\text { de hábitos } \\
\text { letrados y uso } \\
\text { de Quip. }\end{array}$ \\
\hline
\end{tabular}




\section{PRÁCTICAS LETRADAS EN LÍNEA: LA APLICACIÓN DE QUIP EN LA REDACCIÓN DE ESTUDIANTES UNIVERSITARIOS}

Tabla 11

Respuestas de los Docentes

\begin{tabular}{|c|c|c|c|c|c|}
\hline $\mathrm{D}$ & $\begin{array}{l}\text { Aplicación } \\
\text { empleada }\end{array}$ & $\begin{array}{c}\text { Justificación de } \\
\text { uso }\end{array}$ & Etapa que apoyó & $\begin{array}{l}\text { Etapa que no } \\
\text { apoyó }\end{array}$ & $\begin{array}{l}\text { Afinidad con las } \\
\text { prácticas letradas en } \\
\text { línea personales y } \\
\text { educativas }\end{array}$ \\
\hline D1 & Quip & $\begin{array}{l}\text { Beneficioso para } \\
\text { el alumnado: } \\
\text { especialmente } \\
\text { para un alumnado } \\
\text { joven, dinámico y } \\
\text { tecnologizado. }\end{array}$ & $\begin{array}{l}\text { Textualización: } \\
\text { motiva la redacción } \\
\text { colaborativa } \\
\text { y facilita la } \\
\text { interacción } \\
\text { docente-alumno. }\end{array}$ & $\begin{array}{l}\text { Revisión } \\
\text { de fuentes } \\
\text { (preescritura): } \\
\text { dificultad } \\
\text { al trabajar } \\
\text { organizadores } \\
\text { gráficos y } \\
\text { diagramas. }\end{array}$ & $\begin{array}{l}\text { Afín EVA y EPA: } \\
\text { labores académicas } \\
\text { y personales, debido } \\
\text { a que la opción de } \\
\text { escritura en tiempo } \\
\text { real es multisoporte. }\end{array}$ \\
\hline $\mathrm{D} 2$ & $\begin{array}{l}\text { Google } \\
\text { Docs }\end{array}$ & $\begin{array}{l}\text { Conocimiento } \\
\text { previo del } \\
\text { docente: más } \\
\text { práctico, } \\
\text { multisoporte. }\end{array}$ & $\begin{array}{l}\text { Textualización: } \\
\text { redacción } \\
\text { simultánea y acceso } \\
\text { al trabajo de otros } \\
\text { compañeros. }\end{array}$ & $\begin{array}{l}\text { Revisión } \\
\text { de fuentes } \\
\text { (preescritura): } \\
\text { escasa dificultad } \\
\text { al incluir } \\
\text { organizadores } \\
\text { gráficos. }\end{array}$ & $\begin{array}{l}\text { Afín EVA y EPA: útil } \\
\text { y productiva para } \\
\text { mis labores. }\end{array}$ \\
\hline
\end{tabular}

También existe consenso en cuanto a las debilidades de Quip como apoyo al proceso de redacción. Estas se focalizan en las limitaciones técnicas en cuanto a la revisión de fuentes y la planificación. Tal es así que son asociadas a la dificultada para, a través del editor de texto, insertar gráficos, esquemas y diagramas. Asimismo, se evidenció, en uno de los testimonios, la necesidad de un cambio en la estrategia didáctica con respecto a estas fases. En el diseño de actividades individuales, se propuso la revisión de fuentes a través de capturas de pantallas de las fuentes investigadas. Al parecer, los alumnos prefieren la colocación de hipervínculos o la posibilidad de subir documentos enteros por medio del chat o el editor de documentos. 


\section{Conclusiones}

Una vez realizado el análisis y la interpretación de datos, se plantearán las siguientes conclusiones, las cuales involucran los objetivos específicos propuestos:

- En cuanto a las prácticas letradas en línea que conforman los hábitos letrados de docentes y alumnos, Quip representó una herramienta de práctica letrada en línea potencialmente explotable en el acercamiento de los EVA y EPA de los involucrados. Será posible optimizar esta relación si el curso de Comunicación modula el uso de Quip como estrategia didáctica de acuerdo con los vínculos y posibilidades planteados en los diagnósticos presentados, los cuales se apoyan en la transmisión y adquisición de habilidades relativas a las prácticas de escritura y lectura en función de las relaciones docente-alumno e institución-docente.

- En cuanto al uso de Quip como estrategia didáctica complementaria de la didáctica de la redacción, la aplicación Quip en el curso de Comunicación apoyó significativamente el desarrollo de la redacción de (a) la versión preliminar, (b) la retroalimentación 1, (c) la reescritura y (d) la retroalimentación 2 (evaluación), enfocada en la función de chat con los usuarios del documento o carpeta, lo cual significó la activación de la ventaja de monitoreo y retroalimentación directa y constante del docente a través del chat.

- En cuanto al proceso de innovación tecnológica de la universidad, Quip es una aplicación que colabora activamente y aporta 
significativamente en el proceso de adopción de un dispositivo institucional y de la blenderización gradual de los cursos de la universidad. La experiencia del empleo de Quip en un curso del Área de Lenguaje, analizada cualitativamente en este trabajo por medio de diagnósticos diseñados exclusivamente en función de los actores concretos del entorno universitario estudiado, puede servir para la elaboración de instrumentos de diseño cuantitativo que establezcan una validez universal. Esto colaboraría en las etapas de control y reajuste del proceso de innovación tecnológica emprendido hasta el 2018, no solo para las aplicaciones de redacción colaborativa, sino para otras plataformas virtuales utilizadas con fines educativos. 


\section{Referencias}

Arenas Hernández, K. (2014). Roles de estudiantes durante la escritura colaborativa: posibilidad de construcción conjunta de aprendizajes [ponencia en el V Encuentro Internacional y IV Nacional de Lectura y Escritura en la Educación Superior. Recuperado de http:// media.utp.edu.co/referencias-bibliograficas/uploads/referencias/ ponencia/karina-alejandra-arenaspdf-x8c2a-articulo.pdf

Carrera, M., Sapién, A., \& Piñón, L. (s.f.). Uso del teléfono inteligente con fines académicos. El caso de la Fca. de la UACH.

Cassany, D. (1988). Describir el escribir. Cómo se aprende a escribir. Barcelona, España: Paidós.

Cassany, D. (1999). Construir la escritura. Barcelona, Espańa: Paidós.

Cassany, D. (2006). Análisis de una práctica letrada electrónica. Páginas de Guarda, 2, 99-112.

Cassany, D. (2008). Descripción de algunas prácticas letradas recientes. Análisis lingüístico y propuesta didáctica. Recuperado de http:// www.linred.es/informacion_pdf/LR_informacion_31102008.pdf

Cassany, D. (2012). En_linea. Leer y escribir en la red. Barcelona, España: Anagrama.

Cheicher, A., \& Donolo, D. (2013). Estudiantes universitarios y uso de Facebook. Red de Universidades de Educación a Distancia

Cobo, C., \& Moravec, J.W. (2011). Aprendizaje invisible. Hacia una nueva ecología de la educación. Barcelona, España: UB. 


\section{PRÁCTICAS LETRADAS EN LÍNEA: LA APLICACIÓN DE QUIP EN LA REDACCIÓN DE ESTUDIANTES UNIVERSITARIOS}

Díaz, N. (7 de setiembre de 2013). Quip... o la reinvención del procesador de textos. La Tercera, p. 27.

Gómez, M., Roses, S., \& Farías, P. (2012). El uso académico de las redes sociales en universitarios. DOI: 10.3916/C38-2011-03-04

Islas, C., \& Carranza, M. (2011). Uso de las redes sociales como estrategias de aprendizaje. ¿Transformación educativa? Revista de innovación educativa, 3(2). Recuperado de http://www.udgvirtual.udg.mx/ apertura/index.php/apertura/article/view/198/213

Morató, A. (2014). El WhatsApp como complemento de aprendizaje en la clase de E/LE. Foro de profesores de E/LE, 10. Recuperado de http:// foroele.es/revista

Rocha, A. (s.f.). Experiencias y acciones concretas relacionadas con la educación mediática en el ámbito dela educación formal. Recuperado de http:/www.educacionmediatica.es/comunicaciones/Eje\%202/ Alejandra\%20Rocha\%20Silva.pdf

Sanz, C., \&Zangara,A. (2012). Laescrituracolaborativacomo unae-actividad. Ponencia presentada en el XVIII Congreso Argentino de Ciencias de la Computación, Instituto de Investigación en Informática de la Universidad Nacional de La Plata, Argentina. Recuperado de http://sedici.unlp.edu.ar/bitstream/handle/10915/23661/4810La_escritura_colaborativa_como_una_e_final.pdf;jsessionid=C60 DDC4AF71CEB843F395214F33B8157? sequence=1

Serafini, M. (1994). Cómo se escribe. Barcelona, España: Paidós. 